\title{
Influence of Preaging Temperature on the Indentation Strength of 3Y-TZP Aged in Ambient Atmosphere
}

\author{
Ki-Won Jeong ${ }^{1}$, Jung-Suk Han ${ }^{1}$, Gi-Uk Yang ${ }^{2}$ and Dae-Joon Kim ${ }^{2, *}$ \\ 1 Department of Prosthodontics, School of Dentistry and Dental Research Institute, Seoul National University, \\ Seoul 03080, Korea; jkw857@gmail.com (K.-W.J.); proshan@snu.ac.kr (J.-S.H.) \\ 2 VASIC Research Center, Department of Dentistry, School of Dentistry and Dental Research Institute, \\ Seoul National University, Seoul 03080, Korea; clemp1234@gmail.com \\ * Correspondence: djkim2014@gmail.com; Tel.: +82-10-3761-7831
}

check for updates

Citation: Jeong, K.-W.; Han, J.-S.; Yang, G.-U.; Kim, D.-J. Influence of Preaging Temperature on the Indentation Strength of 3Y-TZP Aged in Ambient Atmosphere. Materials 2021, 14, 2767. https://doi.org/ $10.3390 /$ ma14112767

Academic Editor: Kenji Kaneko

Received: 30 April 2021

Accepted: 21 May 2021

Published: 23 May 2021

Publisher's Note: MDPI stays neutral with regard to jurisdictional claims in published maps and institutional affiliations.

Copyright: (c) 2021 by the authors. Licensee MDPI, Basel, Switzerland. This article is an open access article distributed under the terms and conditions of the Creative Commons Attribution (CC BY) license (https:// creativecommons.org/licenses/by/ $4.0 /)$.

\begin{abstract}
Yttria-stabilized zirconia (3Y-TZP) containing $0.25 \% \mathrm{Al}_{2} \mathrm{O}_{3}$, which is resistant to low temperature degradation (LTD), was aged for $10 \mathrm{~h}$ at $130-220^{\circ} \mathrm{C}$ in air. The aged specimens were subsequently indented at loads ranging from 9.8 to $490 \mathrm{~N}$ using a Vickers indenter. The influence of preaging temperature on the biaxial strength of the specimens was investigated to elucidate the relationship between the extent of LTD and the strength of zirconia restorations that underwent LTD. The indented strength of the specimens increased as the preaging temperature was increased higher than $160^{\circ} \mathrm{C}$, which was accompanied by extensive $\mathrm{t}-\mathrm{ZrO}_{2}$ (t) to $\mathrm{m}-\mathrm{ZrO}_{2}$ (m) and c- $\mathrm{ZrO}_{2}$ (c) to $\mathrm{r}-\mathrm{ZrO}_{2}(\mathrm{r})$ phase transformations. The influence of preaging temperature on the indented strength was rationalized by the residual stresses raised by the $t \rightarrow m$ transformation and the reversal of tensile residual stress on the aged specimen surface due to the indentation. The results suggested that the longevity of restorations would not be deteriorated if the aged restorations retain compressive residual stress on the surface, which corresponds to the extent of $\mathrm{t} \rightarrow \mathrm{m}$ phase transformation less than $52 \%$ in ambient environment.
\end{abstract}

Keywords: zirconia; aging; Vickers indentation; phase transformation; biaxial strength

\section{Introduction}

Zirconia is currently one of the most commonly used ceramic materials in restorative dentistry. The application of the first generation of $3 \mathrm{~mol} . \% \mathrm{Y}_{2} \mathrm{O}_{3}$-stabilized tetragonal zirconia polycrystal (3Y-TZP) was limited to frameworks for all-ceramic restorations, on which feldspathic porcelain was layered, owing to its insufficient translucency [1]. However, veneering is a technique sensitive and time-consuming procedure, accompanied by significant tooth reduction and a high risk of chipping, which is a major cause of failure in zirconia veneering ceramics [2,3]. To alleviate such drawbacks, the monolithic zirconia restorations are adapted [4]. However, there are concerns regarding low temperature degradation (LTD) because monolithic zirconia restorations are directly exposed to the humid oral environment and masticatory force. The extent of LTD is determined by the fraction of monoclinic phase of $\mathrm{ZrO}_{2}\left(\mathrm{~m}-\mathrm{ZrO}_{2}\right)$ transformed from tetragonal crystal structure of $\mathrm{ZrO}_{2}$ $\left(\mathrm{t}-\mathrm{ZrO}_{2}\right)$ during aging. Indeed, in vivo aging of $3 \mathrm{Y}$-TZP in the oral environment led to $\sim 12 \%$ of $\mathrm{m}-\mathrm{ZrO}_{2}$ formation after exposing for 24 months [5]. Even 60 days of intra-oral aging of flat 3Y-TZP specimens, exposed to the oral cavity, resulted in $4.7-7.7 \%$ of $\mathrm{m}-\mathrm{ZrO}_{2}$ and deteriorated the strength by 32-39.4\% [6]. LTD is a phenomenon in which $\mathrm{Y}_{2} \mathrm{O}_{3}$-containing $\mathrm{t}-\mathrm{ZrO}_{2}$ transforms to $\mathrm{m}-\mathrm{ZrO}_{2}$ to deteriorate mechanical properties during aging at temperatures of $100-300{ }^{\circ} \mathrm{C}$ and is accelerated in the presence of moisture, such as in the oral environment [7].

LTD is originated from the fact that at ambient temperature $\mathrm{t}-\mathrm{ZrO}_{2}$ is internally strained by the adaptation of $\mathrm{Zr}$ cation in a distorted eightfold coordination environment because the size of $\mathrm{Zr}^{4+}$ is too small to be coordinated to eight oxygen ions in the fluorite 
structure [7]. In the system $\mathrm{ZrO}_{2}-\mathrm{Y}_{2} \mathrm{O}_{3}$, a metastability of $\mathrm{t}-\mathrm{ZrO}_{2}$ is achieved by the substitution of $\mathrm{Y}^{3+}$, whose ionic radius is larger than that of $\mathrm{Zr}^{4+}$, for $\mathrm{Zr}^{4+}$. The substitution leads to the formation of oxygen vacancies and $\mathrm{ZrO}_{7}$ oxygen polyhedron due to the lower valency of $\mathrm{Y}^{3+}$ than $\mathrm{Zr}^{4+}$. LTD relieves the internal stress by leaving the $\mathrm{Zr}$ cation in sevenfold coordination with the oxygen ions, which is found in $\mathrm{m}-\mathrm{ZrO}_{2}$. The activation energy for LTD was determined to be $\sim 83 \mathrm{~kJ} / \mathrm{mol}$ [7] that is in excellent agreement with the measured and theoretical values for the ionic conductivity of 3Y-TZP whose governing mechanism is the oxygen vacancy diffusion [8-10]. Based on the identical activation enthalpies, it was proposed that LTD is attributed to oxygen vacancy diffusion $[7,8]$. That is, LTD on the surface proceeds to relieve the residual stress, which accumulates as a result of the reduction in the oxygen vacancy concentration with prolonged aging at low temperatures. The observation of LTD selectively on the anode-sided surface under an applied electric field further supports that the depletion of the positively charged oxygen vacancies leads to LTD $[8,11]$.

A mechanism, proposed alternatively, is that $\mathrm{O}^{2-}$ originating from the dissociation of water, and not $\mathrm{OH}^{-}$, fills the oxygen vacancies within the crystal lattice, destabilizing the $\mathrm{t}$ $\mathrm{ZrO}_{2}$ to lead LTD [12]. Chevalier et al. have determined the activation energy for the aging of 3Y-TZP to be $106 \mathrm{~kJ} / \mathrm{mol}$ and fitted the aging kinetics in the Mehl-Avrami-Johnson law to allow a prediction of the $\mathrm{m}-\mathrm{ZrO}_{2}$ fraction at the surface of the aged 3Y-TZP for a given time and temperature [13]. This led to the proposal of extrapolation of low temperature degradation rate from accelerated aging tests for the lifetime prediction of medical grade zirconia, that is, a steam sterilization at $134^{\circ} \mathrm{C}$ for $5 \mathrm{~h}$ simulates $15-20$ years at $37^{\circ} \mathrm{C}$ [14]. The generally accepted extrapolation has been questioned by the fact that the extrapolation underestimates LTD in vivo $[5,15]$ and even can lead to unacceptable conclusions about the lifetime of the zirconia-based components [16]. This is because the extrapolation depends heavily on the activation energy and the uncertainty associated with the determination of the activation energy is generally high $[15,16]$.

The severity of LTD has been characterized by measuring the extent of $\mathrm{t}-\mathrm{ZrO}_{2}$ to $\mathrm{m}-\mathrm{ZrO}_{2}(\mathrm{t} \rightarrow \mathrm{m})$ phase transformation mainly using the change in the peak intensities of the $X$-ray diffraction (XRD) patterns of each phase after aging under various conditions [17,18]. Garvie and Nicholson [17] estimated the fraction of transformation by the peak intensity ratio of $[\mathrm{m}(\overline{1} 11)+\mathrm{m}(111)] /[\mathrm{m}(\overline{1} 11)+\mathrm{m}(111)+\mathrm{t}(101)], \mathrm{X}_{\mathrm{m}}$, assuming that the intensity of tetragonal $t(101)$ (or cubic (111)) peak is equal to the sum of the intensities of monoclinic $\mathrm{m}(\overline{1} 11)$ and $\mathrm{m}(111)$ peaks. However, the linear concentration relationship is not strictly correct so that Toraya et al. [18] refined the ratio to $1.311 \mathrm{X}_{\mathrm{m}} /\left(1+0.311 \mathrm{X}_{\mathrm{m}}\right)$ utilizing the Garvie and Nicholson's ratio. The nonlinear calibration was suggested because the theoretical X-ray intensities of the peaks predict an inequality of the intensities, that is, $t(101)>\mathrm{m}(\overline{1} 11)$ $+\mathrm{m}(111)$ [19]. In realty the transformation in LTD always companies with an asymmetric broadening of the $\mathrm{t}(101)$ peak that has been described as the formation of rhombohedral $\mathrm{ZrO}_{2}\left(\mathrm{r}-\mathrm{ZrO}_{2}\right)[7,20]$ and cubic $\mathrm{ZrO}_{2}\left(\mathrm{c}-\mathrm{ZrO}_{2}\right)$ [21]. The additional phases should cause an error in determining the precise extent of LTD and consequently result in the uncertainty in the determination of the activation energy involved in LTD. The error stems from the fact that the quantitative analyses are based on the simple mixtures of constitute monoclinic and tetragonal (cubic) $\mathrm{ZrO}_{2}$ powders [17-19] so that they cannot account for the formation of additional residual stress-assisted $\mathrm{r}-\mathrm{ZrO}_{2}[7,20]$ and the decrease of $\mathrm{c}-\mathrm{ZrO}_{2}$ [20] as LTD proceeds. It is noteworthy that the activation energy of $106 \mathrm{~kJ} / \mathrm{mol}$ was obtained from the $\mathrm{m}-\mathrm{ZrO}_{2}$ fraction determined by 'a modified Garvie and Nicholson equation' [13] and the $83 \mathrm{~kJ} / \mathrm{mol}$ was calculated after stripping off the contributions of $\mathrm{r}-\mathrm{ZrO}{ }_{2}$ and $\mathrm{c}-\mathrm{ZrO}_{2}$ from the intensity of $\mathrm{t}(101)$ peak of $\mathrm{t}-\mathrm{ZrO}_{2}$ [7].

The effect of LTD on the mechanical properties has been quite controversial. Some reports state that the increase in flexural strength with LTD results from transformation toughening to induce compressive stress on the surface [22-24]. Conversely, the decrease in strength may be because the number of micro-cracks around the grains formed by aging is sufficient to cause an imbalance with the compressive stress [25-27]. Finally, the mechanical 
property is not affected by aging because the aging conditions, such as aging temperature or time, are not sufficient to influence the strength [28-30]. Thus, the influence of LTD on the flexural strength of 3Y-TZP has not been clearly elucidated.

Ceramics become fractured when the applied stress intensity exceeds the critical stress intensity factor, that is, the fracture toughness. Intrinsic flaws that control the strength can be introduced during the fabrication process such as powder compaction, forming, drying, firing, and cooling [31]. Conversely, extrinsic flaws can be introduced into dental ceramics by dental clinicians or technicians during grinding or polishing ceramic restorations [31], as well as because of masticatory force or parafunctional habits such as bruxism and clenching [32]. Such extrinsic damages may cause reduced strength, resulting in premature failure of dental ceramics [33]. Although dental 3Y-TZPs are strong enough to withstand the extrinsic damages $[34,35]$, the damage coupled with LTD may become a strength limiting flaw. Nevertheless, there has been no systematic attempt to evaluate the influence of extrinsic stimuli on the strength of monolithic zirconia restorations encountered by LTD. To simulate the extrinsic flaws, Vickers indentation was applied to the 3Y-TZP that was aged in ambient atmosphere prior to the indentation. Although the indentation loads used in this study are slightly higher than the mastication load, a comparable damage may occur in procedure of grinding or polishing by dental clinicians or technicians during dental practices [33]. In this study, the extent of LTD was evaluated using the Rietveld refinement and the influence of preaging temperature on the strength of 3Y-TZP, aged in air and then indented, was investigated to elucidate the aging dependence of strength.

\section{Materials and Methods}

3Y-TZP powder was used for the specimens and the material information is listed in Table 1 . The powder was pressed uniaxially at $125 \mathrm{MPa}$ in a steel die, then pressed isostatically at $186 \mathrm{MPa}$ to produce pellet-shaped green compacts (diameter: $20 \mathrm{~mm}$, height: $1.5 \mathrm{~mm}$ ). The pressed specimens were debinded for $55 \mathrm{~h}$ up to $985^{\circ} \mathrm{C}$, and then sintered for $2-20 \mathrm{~h}$ at $1550^{\circ} \mathrm{C}$ on an alumina crucible in air. To prevent potential interaction between the specimens and the crucible, the top surface of the sintered specimens was used exclusively for XRD and indentation. After sintering, the diameter and thickness of the specimens were $15.7 \pm 0.05 \mathrm{~mm}$ and $1.22 \pm 0.04 \mathrm{~mm}$, respectively. No surface treatment was performed prior to the experiments.

Table 1. Material information for 3Y-TZP utilized in the present study *.

\begin{tabular}{cccc}
\hline Brand Name & Composition & Lot No. & Manufacturer \\
\hline & $\mathrm{Y}_{2} \mathrm{O}_{3} 5.2 \pm 0.5$ & & \\
$\mathrm{HfO}_{2} \leq 5.0$ & & \\
& $\mathrm{Al}_{2} \mathrm{O}_{3} \leq 0.1-0.4$ & T309336B & \\
$\mathrm{SiO}_{2} \leq 0.02$ & & \\
& $\mathrm{Fe}_{2} \mathrm{O}_{3} \leq 0.01$ & & \\
& $\mathrm{Na}_{2} \mathrm{O} \leq 0.06$ & & \\
&
\end{tabular}

Initially, 20 specimens of each were sintered at $1550^{\circ} \mathrm{C}$ for $2,8,14$, and $20 \mathrm{~h}$, and half of each group was indented at $9.8 \mathrm{~N}$. After the initial trials, 350 pellets were fabricated by sintering at $1550{ }^{\circ} \mathrm{C}$ for $20 \mathrm{~h}$ and randomly divided into five groups $(n=70)$ based on aging temperatures of $130,160,190$, and $220^{\circ} \mathrm{C}$, including as-sintered specimens for the control. Each group of specimens was subdivided again by 10 specimens for indentations at loads of $0,9.8,49,98,196,294$, and $490 \mathrm{~N}$. All specimens were aged for $10 \mathrm{~h}$ at each temperature in air prior to the indentations. The microstructures of the sintered specimens, thermally etched for $15 \mathrm{~min}$ at $1500{ }^{\circ} \mathrm{C}$, were observed using a scanning electron microscope (SEM, S4700, Hitachi, Tokyo, Japan) at $\times 30,000$ magnifications with an accelerating voltage of $20 \mathrm{kV}$. 
The bulk density of the fully sintered blocks was determined in accordance with ISO/DIS 18754 [36], using distilled water as the immersion liquid. The $\mathrm{m}-\mathrm{ZrO}_{2}$ fraction was determined using Rietveld refinements from the XRD data for the specimens, which were collected on a Bragg-Brentano diffractometer (PANalytical, Almelo, The Netherlands) with a CuK $\alpha$ X-ray tube, a Bragg-BrentanoHD optical module, a position-sensitive PIXcel3D detector, and Soller slits (0.02 rad). The scan range covered $2 \theta=20-90^{\circ}$ at a step size of $\Delta 2 \theta=0.0217^{\circ}$. The data reduction and structure determination from the XRD data were performed using the HighScore Plus suite.

For the Vickers indentations, predetermined loads ranging from 9.8 to $490 \mathrm{~N}$ were indented for $10 \mathrm{~s}$ at the center of each specimen using a digital Vickers hardness tester (Highwood HWDV-7, TTS Unlimited Inc., Osaka, Japan). Immediately after unloading, a drop of silicon oil was applied on the indented surface to prevent possible humidity assisted-crack growth. The biaxial flexural strength was determined in accordance with the ISO 6872:2015 standard for dental ceramics [37]. The indented surface of each specimen was positioned to face the three supporting steel balls (diameter: $2.7 \mathrm{~mm}$ ), positioned $120^{\circ}$ apart on a support circle, then loaded at a crosshead speed of $1.0 \mathrm{~mm} / \mathrm{min}$ using a universal testing machine (Instron 3365, Canton, MA, USA). To avoid contact damage, an ethylene-vinyl acetate foil was inserted between a flat punch (diameter: $1.4 \mathrm{~mm}$ ) and specimen to ascertain an even contact.

Statistical analyses were performed using $\mathrm{R}$ software (version 3.6.2, R Foundation for Statistical Computing, Vienna, Austria). As the data showed non-normal distribution, they were analyzed using non-parametric statistical test, aligned rank transform analysis of variance (ART ANOVA), and multiple comparison using Bonfferoni post hoc test. The effect of independent variables such as the aging temperature and indentation load on biaxial strength, and the interaction of the two independent variables were determined. For all statistical analyses, a significance level of 5\% was used.

\section{Results}

The SEM micrographs of 3Y-TZP sintered at $1550{ }^{\circ} \mathrm{C}$ for $2-20 \mathrm{~h}$ are shown in Figure 1. After sintering for $2 \mathrm{~h}$, the grain boundaries were well defined, and the size was determined to be $0.53 \mu \mathrm{m}$ (Figure 1a) and increased to $0.72 \mu \mathrm{m}$ after sintering for $8 \mathrm{~h}$ (Figure 1b). As time further increased, the grain boundaries became obscure because of pulverization of the grains into pristine grains. The unclear boundaries and pulverization made it difficult to determine the grain sizes after sintering longer than $14 \mathrm{~h}$ (Figure 1c,d). The XRD patterns of the specimens revealed that the $\mathrm{t} \rightarrow \mathrm{m}$ phase transformation extended with the sintering time as demonstrated by the increase in the peak heights for $\mathrm{m}-\mathrm{ZrO}_{2}$ and the decrease in the peak intensity of $\mathrm{t}-\mathrm{ZrO}_{2}$ in Figure 2. This suggests that the uneven microstructures were mainly due to the volume expansion accompanied by the $t \rightarrow m$ phase transformation and boosted because of thermal etching after polishing for SEM observations, which may ease the restriction that retained the pristine grains inside the grain boundaries.

In Figure 2, the increase in the phase transformation is manifested by the increased peak intensities of $\mathrm{m}-\mathrm{ZrO}_{2}$ along with an asymmetric broadening of the (101) peak of $\mathrm{t}-\mathrm{ZrO}_{2}$ with increasing sintering time. After sintering for $14 \mathrm{~h}$ the broadening of the peak at $30^{\circ}$ becomes visible. The peak for $\mathrm{c}(111)$ is imbedded in the peak of $t(101)$ and the peak for $\mathrm{c}(020)$ is shown as a separate peak at $35.2^{\circ}$ between two $\mathrm{t}-\mathrm{ZrO}_{2}$ peaks. The markers for $\mathrm{r}-\mathrm{ZrO}_{2}$ related to the broadening are supposed to appear at $2 \theta$ of $\sim 30^{\circ}$ and $\sim 35^{\circ}$ but are not apparent because the extent of $\mathrm{c} \rightarrow \mathrm{r}$ phase transformation is limited. The peak intensity of $\mathrm{m}(111)$ at $31.5^{\circ}$ for $\mathrm{m}-\mathrm{ZrO}_{2}$ is so weak that the peak intensity ratio of $\mathrm{m}(111) / \mathrm{m}(111)$ is anomalously high compared to the ratio of 1.47 that is found in the ICDD \# 00-037-1484 for $\mathrm{m}-\mathrm{ZrO}_{2}$. In the XRD pattern for $20 \mathrm{~h}$ it is interesting to note that the peak intensity of $\mathrm{m}(002)$ at $34.2^{\circ}$ is higher than that of $\mathrm{m}(111)$ even though the intensities are listed as 21 and 68 , respectively. No peak overlapping for $\mathrm{m}-\mathrm{ZrO}_{2}$ was observed in the entire scan range. 

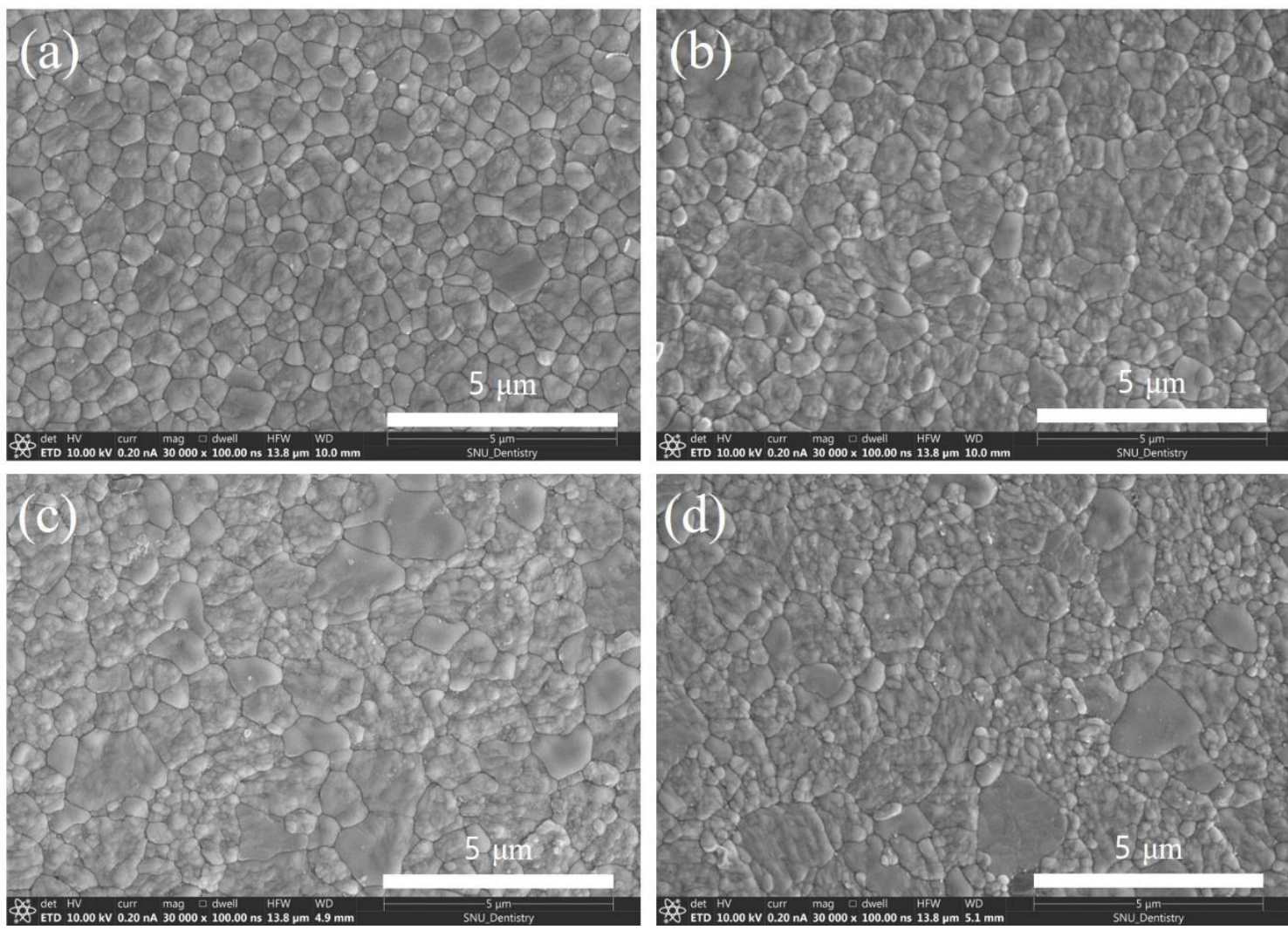

Figure 1. Scanning electron micrographs of $3 \mathrm{Y}-\mathrm{TZP}$ sintered at $1550{ }^{\circ} \mathrm{C}$ for (a) $2 \mathrm{~h},(\mathbf{b}) 8 \mathrm{~h}$, (c) $14 \mathrm{~h}$, and (d) $20 \mathrm{~h}$. The specimen, sintered for $2 \mathrm{~h}$, shows fine grain size and well-defined grain boundaries. As the sintering time increases, the grain size increases and the grain boundaries became obscured by the disintegration of grains into pristine ones.

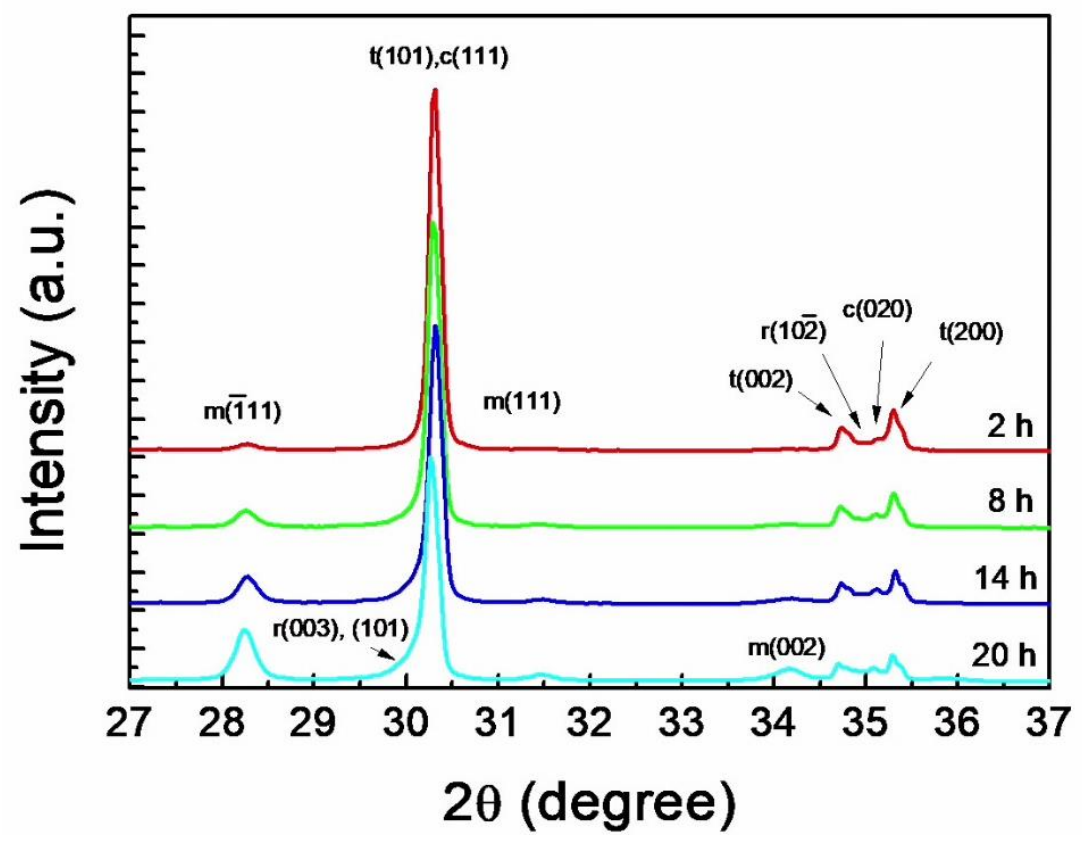

Figure 2. X-ray diffraction patterns of $3 \mathrm{Y}$-TZP sintered for $2-20 \mathrm{~h}$ at $1550{ }^{\circ} \mathrm{C}$. The (101) peak of $\mathrm{t}-\mathrm{ZrO}_{2}$ is overlapped with (111) peak of $\mathrm{c}-\mathrm{ZrO}_{2}$ and (003) and (101) peaks of $\mathrm{r}-\mathrm{ZrO}_{2}$ to display an asymmetric broadening. The depth of broadening is proportional to the extent of $t \rightarrow m$ phase transformation.

In Figure 3 the $\mathrm{t}(101)$ peak at $30.2^{\circ}$ from the 3 Y-TZP sintered for $20 \mathrm{~h}$ at $1550{ }^{\circ} \mathrm{C}$ was deconvoluted into $\mathrm{t}-, \mathrm{r}-$, and $\mathrm{c}-\mathrm{ZrO}_{2}$ phases by the Rietveld refinement. All peaks 
including the asymmetric peak were well identified with the given structure models including $\mathrm{r}$ - and $\mathrm{c}-\mathrm{ZrO}_{2}$ phases. The Rietveld refinement revealed that the asymmetric peak is composed of $\mathrm{r}(003)$ at $29.8^{\circ}$ and $\mathrm{r}(101)$ at $30.0^{\circ}$ of $\mathrm{r}-\mathrm{ZrO}_{2}$ and $\mathrm{c}(111)$ at $30.2^{\circ}$ of $\mathrm{c}-\mathrm{ZrO}_{2}$ besides $\mathrm{t}(101)$ of $\mathrm{t}-\mathrm{ZrO}_{2}$. Thus, $\mathrm{c}-\mathrm{ZrO}_{2}$ completely overlaps $\mathrm{t}-\mathrm{ZrO}_{2}$ in the asymmetric peak. The deconvolution of the compound peak at $\sim 35^{\circ}$ showed the $\mathrm{r}(10 \overline{2})$ peak of $\mathrm{r}-\mathrm{ZrO}_{2}$ at $34.8^{\circ}$ embedded near the $\mathrm{c}(020)$ peak of $\mathrm{c}-\mathrm{ZrO}_{2}$ at $35.1^{\circ}$. In this study the extent of $\mathrm{t} \rightarrow \mathrm{m}$ transformation was determined by the volume fraction ratio of $\mathrm{m}-\mathrm{ZrO} \mathrm{O}_{2} /\left(\mathrm{m}-\mathrm{ZrO}_{2}+\mathrm{t}-\mathrm{ZrO}_{2}\right)$ based on the analysis by the Rietveld refinement procedure. The $\mathrm{m}-\mathrm{ZrO}_{2}$ volume fractions in the specimens sintered at $1550{ }^{\circ} \mathrm{C}$ for $2,8,14$, and $20 \mathrm{~h}$ (Figure 2) were calculated to be $15.4,27.7,39.6$, and $44.6 \%$, respectively.

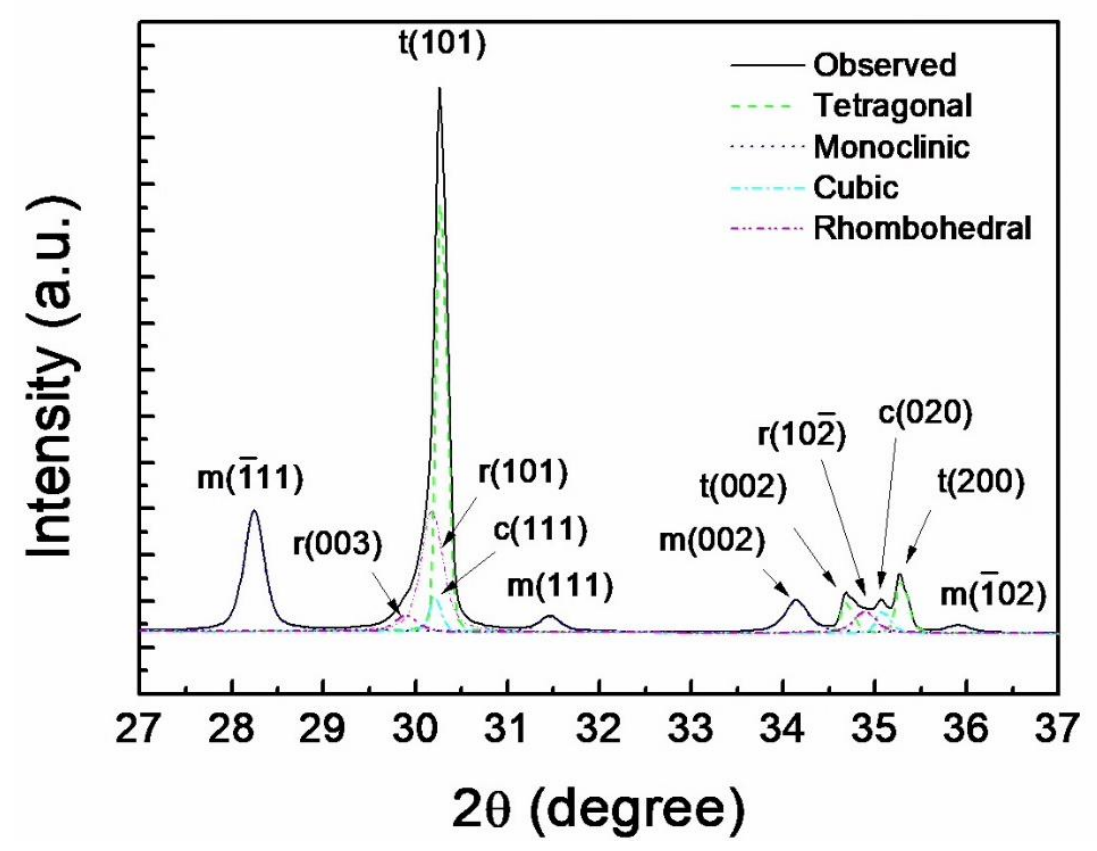

Figure 3. Deconvolution of asymmetric (101) peak of $\mathrm{t}-\mathrm{ZrO}_{2}$ into (003) and (101) peaks of $\mathrm{r}-\mathrm{ZrO}_{2}$ and (111) peak of c-ZrO $\mathrm{rO}_{2}$ from 3Y-TZP sintered for $20 \mathrm{~h}$ at $1550{ }^{\circ} \mathrm{C}$. The overlapping becomes more evident at $2 \theta$ of $\sim 35^{\circ}$ where $r(10 \overline{2})$ and $c(020)$ are separated from $t(002)$ and $t(200)$. No overlapping for $\mathrm{m}-\mathrm{ZrO}_{2}$ is observed.

The influence of the $\mathrm{m}-\mathrm{ZrO}$ fraction, originated from the different sintering time (Figure 1), on the biaxial strength is depicted in Figure 4. The strength of the as-sintered specimens tended to decrease steadily upon the fraction. Conversely, the strength increased asymptotically with the fraction when $9.8 \mathrm{~N}$ of indentation was applied to the specimens. Although the strength of the indented specimen sintered for $2 \mathrm{~h}$ was lower than that of the as-sintered specimen by $334 \mathrm{MPa}$, the difference became nullified for the specimen sintered for $20 \mathrm{~h}$. The decrease and increase in strength of the as-sintered and indented specimens, respectively, with the sintering time are likely influenced by both the enlargement of the grain size (Figure 1) and the increase in the extent of $t \rightarrow m$ phase transformation (Figure 2). 


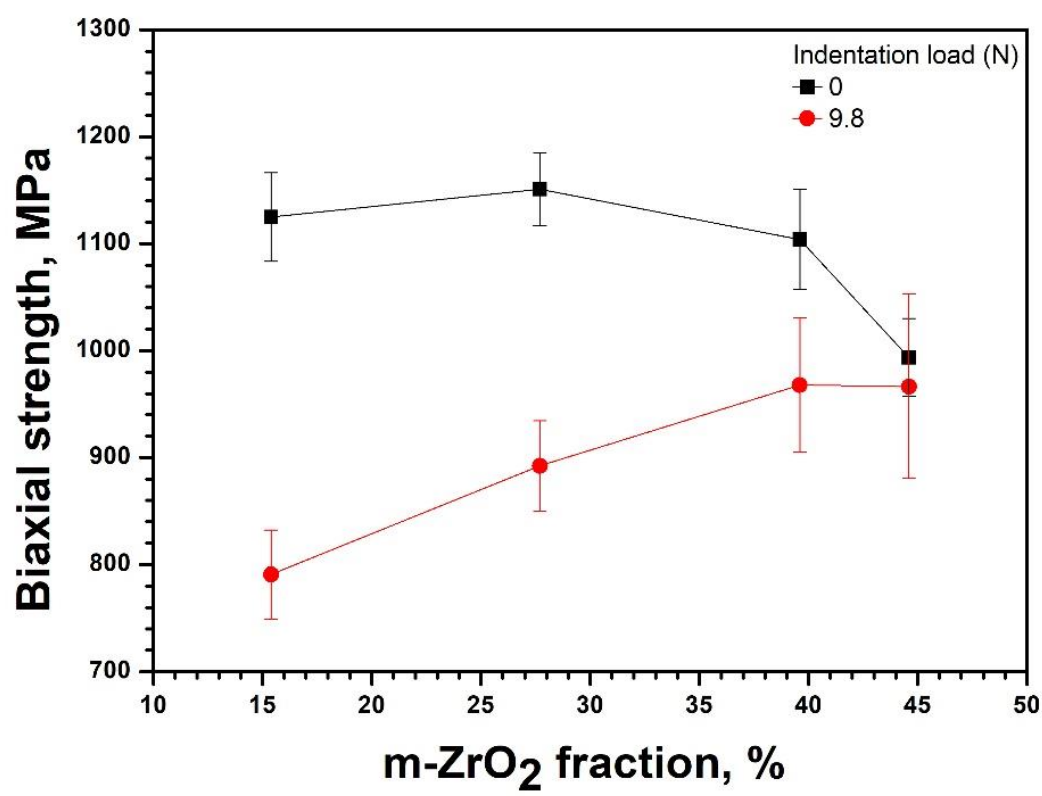

Figure 4. Variation of the biaxial strength of the as-sintered 3Y-TZP and the 3Y-TZP indented at $9.8 \mathrm{~N}$ as a function of $\mathrm{m}-\mathrm{ZrO}_{2}$ fraction that is determined by sintering time. The biaxial strength of as-sintered specimens tends to decrease with $\mathrm{m}-\mathrm{ZrO}_{2}$ fraction, but the strength of the identical specimens indented at $9.8 \mathrm{~N}$ increases with the fraction. The $\mathrm{m}-\mathrm{ZrO}_{2}$ fractions were obtained by Rietveld refinement of 3Y-TZP sintered at $1550{ }^{\circ} \mathrm{C}$ for $2,8,14$, and $20 \mathrm{~h}$ as shown in Figure 2.

The influence of aging temperature on the phase change was shown in Figure 5. The asymmetric broadening of the (101) peak of $\mathrm{t}-\mathrm{ZrO}_{2}$ was also observed and increased in proportion to LTD. After aging at $190{ }^{\circ} \mathrm{C}$ the peak shape of $\mathrm{t}(101)$ disrupted to result in the transformation of $77.7 \mathrm{vol} . \%$ of $\mathrm{t}-\mathrm{ZrO}_{2}$ into $\mathrm{m}-\mathrm{ZrO}_{2}$. Concurrently, the $\mathrm{r}(10 \overline{2})$ became prominent at $34.8^{\circ}$ and a marked preference of the $\mathrm{m}(002)$ orientation at $34.2^{\circ}$ was observed. After aging at $220^{\circ} \mathrm{C}$ the asymmetricity disappeared and $96.8 \mathrm{vol} . \% \mathrm{t}-\mathrm{ZrO}_{2}$ was transformed to $\mathrm{m}-\mathrm{ZrO}_{2}$. The shift of the peak at $30.2^{\circ}$ toward a lower $2 \theta$ and the disappearance of $\mathrm{c}(020)$ at $35.1^{\circ}$ indicate that the $\mathrm{t} \rightarrow \mathrm{m}$ and $\mathrm{c} \rightarrow \mathrm{r}$ phase transformations were nearly completed. The $\mathrm{m}-\mathrm{ZrO}{ }_{2}$ volume fractions in the as-sintered and the specimens aged at 130, 160, 190, and $220^{\circ} \mathrm{C}$ for $10 \mathrm{~h}$ were $35.6,40.9,52.2,77.7$, and $96.8 \%$, respectively.

The Rietveld refinement revealed no significant changes in the lattice parameters of $\mathrm{m}-\mathrm{ZrO}_{2}$ as the aging temperatures increased. However, the lattice constant of $\beta$, the angle between $a$ and $c$ axes, varied with LTD as depicted in Figure 6. The $\beta$ of $99.03^{\circ}$ for the as-sintered 3Y-TZP remained nearly unchanged up to $130^{\circ} \mathrm{C}$, then expanded upon further increasing the temperature suggesting that LTD is closely related to the variation of $\beta$. The lattice constants of the $\mathrm{m}-\mathrm{ZrO}_{2}$ were calculated by the Rietveld refinement through all possible Bragg reflections in the corresponding crystal structures in the XRD pattern. Since it underwent a process of defining the correct peak position through correction of the zero-shift error and/or sample displacement error, the estimated standard deviation involved in $\beta$ ranges from 0.0015 to $0.0036^{\circ}$.

The bulk density of 3Y-TZP sintered at $1550{ }^{\circ} \mathrm{C}$ for $20 \mathrm{~h}$ was $6.01 \mathrm{~g} / \mathrm{cm}^{3}$, corresponding to $98.5 \%$ of the theoretical density $\left(6.10 \mathrm{~g} / \mathrm{cm}^{3}\right)$ of $3 Y-T Z P$. The density decreased slightly as the aging temperature increased from 130 to $220^{\circ} \mathrm{C}$ in Table 2, where all specimens were aged for $10 \mathrm{~h}$ at each temperature. The decrease in density was concurrent with the increase in the extent of $\mathrm{t} \rightarrow \mathrm{m}$ phase transformation (Figure 5) because the theoretical density of $\mathrm{m}-\mathrm{ZrO}_{2}\left(5.83 \mathrm{~g} / \mathrm{cm}^{3}\right)$ is lower than that of $\mathrm{t}-\mathrm{ZrO}_{2}$. 


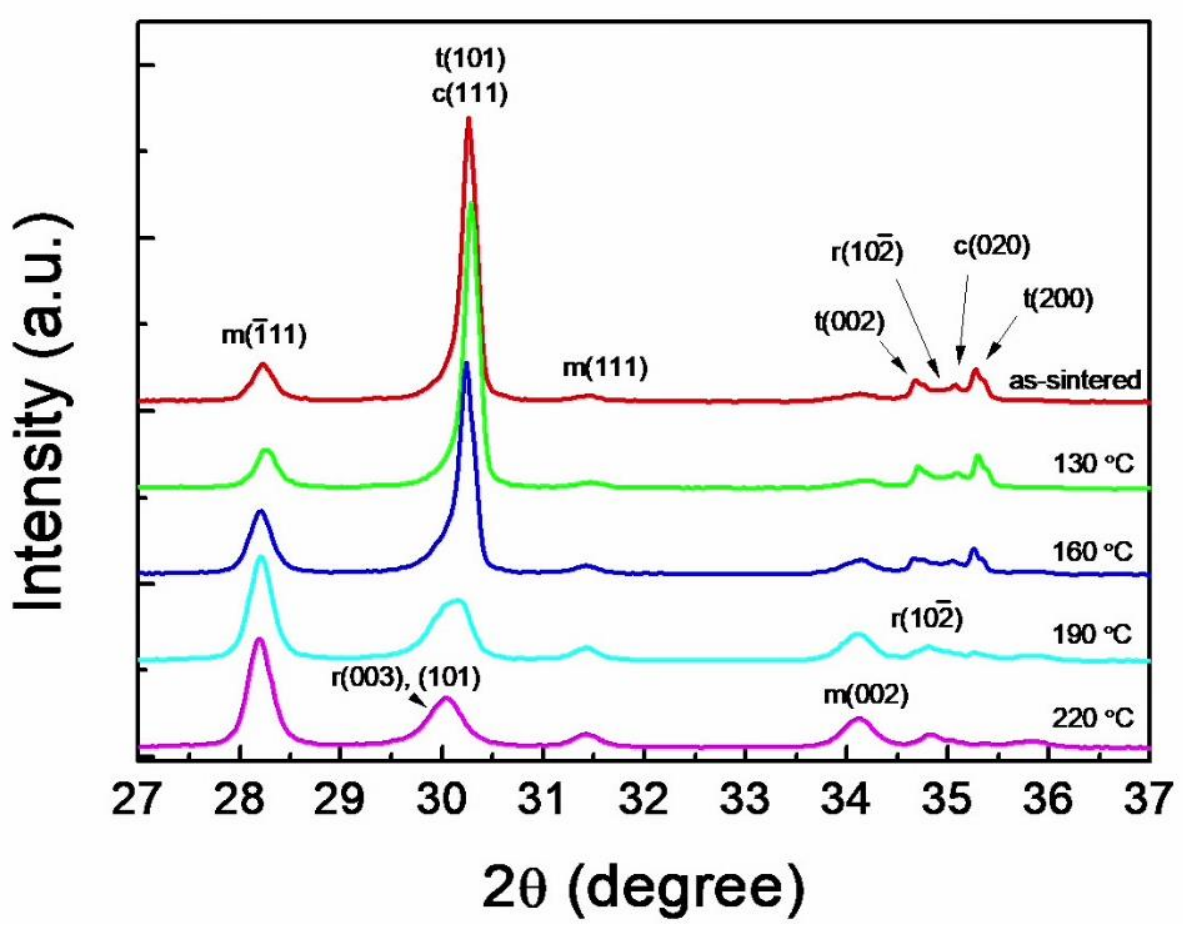

Figure 5. X-ray diffraction patterns of 3Y-TZP aged for $10 \mathrm{~h}$ at temperatures ranging from 130 to $220{ }^{\circ} \mathrm{C}$ after sintering at $1550{ }^{\circ} \mathrm{C}$ for $20 \mathrm{~h}$. The pattern for the as-sintered specimen was added for comparison. The asymmetric broadening, associated with $\mathrm{r}-\mathrm{ZrO}_{2}$ and $\mathrm{c}-\mathrm{ZrO}_{2}$, increases with aging temperature and corresponds to $\mathrm{r}-\mathrm{ZrO}_{2}$ at $220^{\circ} \mathrm{C}$ suggesting that aging results in both $\mathrm{t} \rightarrow \mathrm{m}$ and $\mathrm{c} \rightarrow \mathrm{r}$ phase transformations.

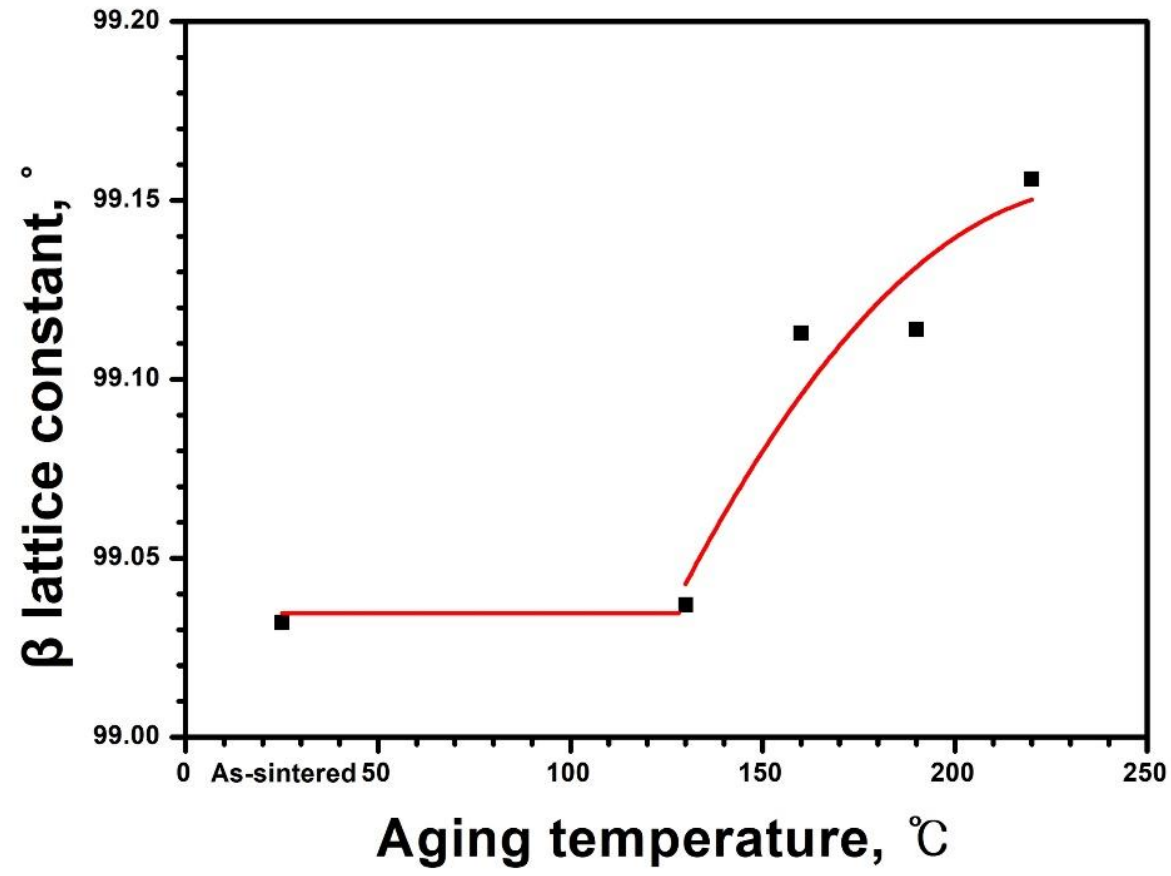

Figure 6. Variation of the $\beta$ lattice constant of $\mathrm{m}-\mathrm{ZrO}_{2}$ of $3 \mathrm{Y}-\mathrm{TZP}$ sintered at $1550{ }^{\circ} \mathrm{C}$ for $20 \mathrm{~h}$ as a function of the aging temperature. The abrupt increase of $\beta$ after aging at $160{ }^{\circ} \mathrm{C}$ indicates that the compressive residual stress in $\mathrm{m}-\mathrm{ZrO}_{2}$ is reduced to some extent. 
Table 2. The bulk density of 3Y-TZP specimens aged for $10 \mathrm{~h}$ in air after sintering for $20 \mathrm{~h}$ at $1550{ }^{\circ} \mathrm{C}$.

\begin{tabular}{cccccc}
\hline \multicolumn{5}{c}{ Aging Temperature, ${ }^{\circ} \mathbf{C}$} \\
\hline & As-sintered & 130 & 160 & 190 & 220 \\
Bulk density, $\mathrm{g} / \mathrm{cm}^{3}$ & $6.01 \pm 0.02$ & $6.01 \pm 0.01$ & $5.97 \pm 0.02$ & $5.97 \pm 0.02$ & $5.96 \pm 0.01$ \\
\hline
\end{tabular}

In Figure 7 the fractions of $\mathrm{t} \rightarrow \mathrm{m}$ transformation for the specimens in Figure 5 were plotted along with the corresponding biaxial strength as a function of the aging temperature. As the aging temperatures increased, the $\mathrm{m}-\mathrm{ZrO}_{2}$ content increased and the biaxial strength decreased, except for aging at $130{ }^{\circ} \mathrm{C}$, showing a slightly higher strength than the assintered specimen even though the $\mathrm{m}-\mathrm{ZrO}_{2}$ fraction was extended moderately from $35.6 \%$ to $40.9 \%$. As the aging temperature increased further, the strength decreased abruptly in the same manner as the increase in the extent of $\mathrm{t} \rightarrow \mathrm{m}$ transformation.

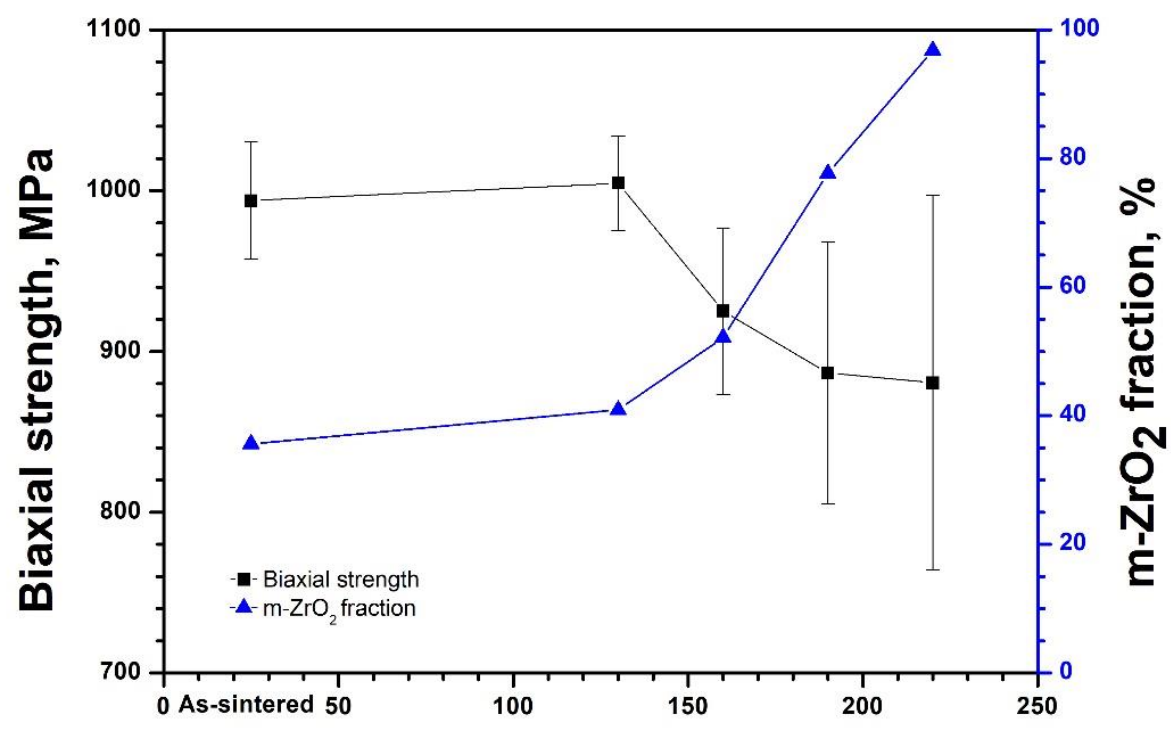

Aging temperature, ${ }^{\circ} \mathrm{C}$

Figure 7. Biaxial strength and fraction of $\mathrm{m}-\mathrm{ZrO}_{2}$ transformed from $\mathrm{t}-\mathrm{ZrO}_{2}$ determined after aging for $10 \mathrm{~h}$ at temperatures ranging from $130^{\circ} \mathrm{C}$ to $220^{\circ} \mathrm{C}$. The results demonstrate the degradation of strength with LTD.

In Figure 8 the involvement of the preaging temperature in the indented strength was demonstrated by the plot of the strength as a function of the temperature. The 3YTZP specimens were sintered at $1550{ }^{\circ} \mathrm{C}$ for $20 \mathrm{~h}$, then aged for $10 \mathrm{~h}$ at $130-220^{\circ} \mathrm{C}$; the as-sintered specimen was included as a control. The specimens were indented at loads ranging from 9.8 to $490 \mathrm{~N}$ prior to the strength measurement and a set of specimens without indentation was added to facilitate comparison. The strength of the indented specimens tended to increase with the preaging temperature, and the increasing trend diminished as the indentation load increased. Similar results were also observed in Figure 4, where the biaxial strength of the specimens indented at $9.8 \mathrm{~N}$ increased with $\mathrm{m}-\mathrm{ZrO}_{2}$ content, which was varied by sintering times at $1550{ }^{\circ} \mathrm{C}$. Notably, the strength of the specimens, aged at $160-220^{\circ} \mathrm{C}$ and then indented with a load of $9.8 \mathrm{~N}$, was higher than the identical specimens without indentation. The contribution of indentation on the increase in strength became progressively prominent up to a load of $98 \mathrm{~N}$, then became less noticeable upon further increasing the loads. Based on the statistical analysis, the aging temperature and indentation load significantly impacted the biaxial flexural strength 3Y-TZP $(p<0.05$, Bonferroni post hoc test). Furthermore, there was significant interaction between two independent variables of preaging temperature and indentation load $(p<0.05$, Bonferroni post hoc test), as listed in Table 3. 


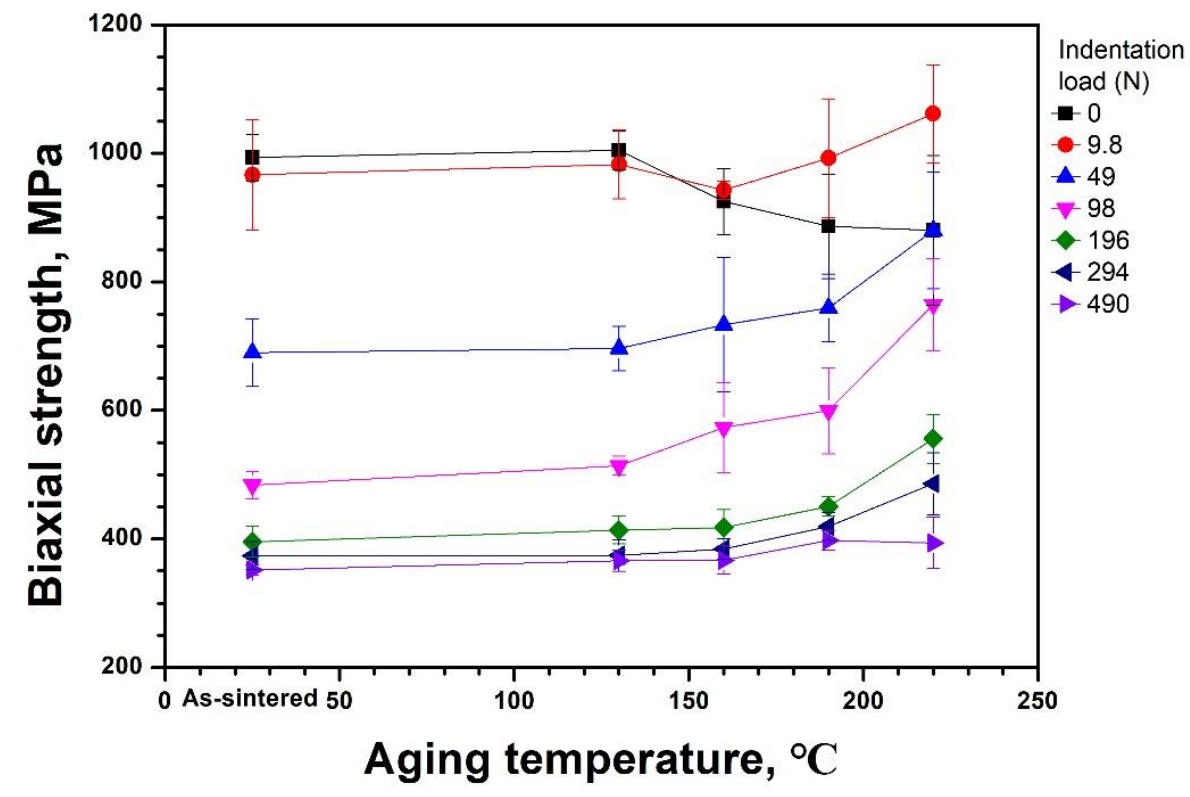

Figure 8. Variation of the biaxial strength of 3Y-TZP indented at loads ranging from 0 to $490 \mathrm{~N}$ as a function of aging temperature. The results show that the indented strength of preaged specimens increases with LTD. The specimens were aged for $10 \mathrm{~h}$ after sintering at $1550{ }^{\circ} \mathrm{C}$ for $20 \mathrm{~h}$. The strength of as-sintered specimen is displayed at the scale of $25^{\circ} \mathrm{C}$.

Table 3. Summary of ART ANOVA for the biaxial flexural strength of indented 3Y-TZP after aging.

\begin{tabular}{cccc}
\hline Source & Df & F Value & $p$ Value \\
\hline Aging temperature & 4 & 42.194 & $<0.001$ \\
Indentation load & 6 & 824.465 & $<0.001$ \\
Aging temperature $\times$ Indentation load & 24 & 10.605 & $<0.001$ \\
\hline
\end{tabular}

\section{Discussion}

This study was initially designed to examine the extent of the $t \rightarrow m$ phase transformation of 3Y-TZP for up to $100 \mathrm{~h}$ at a temperature range of $130-220^{\circ} \mathrm{C}$ at $30^{\circ} \mathrm{C}$ intervals in air. Primary tests showed that the LTD resistant 3Y-TZP containing $0.25 \mathrm{wt} . \% \mathrm{Al}_{2} \mathrm{O}_{3}$, prepared by sintering at $1550{ }^{\circ} \mathrm{C}$ for $2 \mathrm{~h}$, underwent an insignificant amount of phase transformation after aging for $100 \mathrm{~h}$ at the lowest intended temperature of $130^{\circ} \mathrm{C}$. Since it caused difficulty in determining the extent for aging times shorter than $100 \mathrm{~h}$, the 3Y-TZP was sintered at $1550{ }^{\circ} \mathrm{C}$ for $20 \mathrm{~h}$ to expedite the transformation and was used for the remaining experiments. The 3Y-TZP, employed in this investigation, is known to be less vulnerable to LTD because the $\mathrm{Al}_{2} \mathrm{O}_{3}$ content of $0.25 \mathrm{wt}$. \% decreases the grain boundary energy of $\mathrm{t}-\mathrm{ZrO}_{2}$ to suppress LTD as a result of the grain boundary segregation of $\mathrm{Al}^{3+}$ ions [38]. Furthermore, this aging study was performed in ambient atmosphere to minimize the involvement of water species, which has been reported as the cause of LTD in numerous reports on this subject. This study demonstrates that LTD tolerant 3Y-TZP encounters $t \rightarrow m$ phase transformation in an ambient atmosphere, where no intentional water species are involved like autoclave treatments, as 3Y-TZP is stressed internally by the enlargement of grain size.

The $\mathrm{t} \rightarrow \mathrm{m}$ transformation governing LTD proceeds in air as long as the grain size is sufficiently large to cause sufficient residual tensile stress at the grain boundaries and corners [39]. The grain size dependence of the transformation in Figures 1 and 2 stems from the fact that the local tensile stress concentration, due to the thermal expansion anisotropy (TEA) of the $a$ and $c$ axes of tetragonal zirconia lattice, scales with the grain size $[39,40]$. The dependency is manifested by the increased $t \rightarrow m$ phase transformation temperature and fracture toughness with the increase in grain size. The TEA in Y-TZP decreases with increasing $\mathrm{Y}_{2} \mathrm{O}_{3}$ content in $\mathrm{ZrO}_{2}$ [41] leading to the phase stability against 
LTD and consequently to a low fracture toughness of tetragonal zirconia. Conversely, TEA increases with the addition of pentavalent cation oxides, such as $\mathrm{Nb}_{2} \mathrm{O}_{5}$ and $\mathrm{Ta}_{2} \mathrm{O}_{5}$, to Y-TZP [42], resulting in phase instability favorable to LTD [7,8,43] and enhanced fracture toughness $[8,44]$. In this context, the stabilizer for $\mathrm{t}-\mathrm{ZrO}_{2}$, which consequently prevents LTD, can be defined as oxides that reduce TEA when added to $\mathrm{ZrO}_{2}$ to form solid solutions. Due to the dominant contribution of residual stress to LTD, it occurs in environments where no water is involved, such as in vacuum and dried air [43] and moisture-free silicon oil [8], once the tetragonal solid solutions are stressed internally by high TEA, which is commonly accompanied by high $c / a$ axial ratios of the tetragonal lattice [44]. Thus, in this study, the $3 \mathrm{Y}$-TZP containing $\mathrm{Al}_{2} \mathrm{O}_{3}$, which prohibits LTD, experienced extensive LTD at ambient atmosphere because the residual stress was sufficiently large to trigger the phase transformation. These observations confirm that environments containing water or water vapor are not prerequisites for LTD but accelerate LTD $[8,43]$.

Additionally, the residual stress influences the strength of 3Y-TZP in the $t \rightarrow m$ phase transformation, which can be envisaged from the strength of the specimens indented with $9.8 \mathrm{~N}$ in Figure 4 . Without the indentation the strength decreased gradually with the increasing $\mathrm{m}-\mathrm{ZrO}_{2}$ fraction due to the increase in sintering time. The decrease is likely resulted from a combined contribution of the increase in the grain size (Figure 1) in accordance with the Hall-Petch relationship and the $t \rightarrow m$ transformation (Figure 2). However, the increase in the indented strength with the grain sizes suggests that the main reason behind the decrease in the strength is the transformation related residual stress. An analogous trend was also observed when the specimen was aged at $130,160,190$, and $220^{\circ} \mathrm{C}$ for $10 \mathrm{~h}$ in Figure 7, where the influence of grain size is not involved. These observations consist with the reports that the strength decreases with LTD [25-27]. The decrease in the strength has been rationalized based on the argument that when the depth of the transformed layer is greater than the critical crack size of the specimen, determined by the linear fracture mechanics, the strength decreases in proportion to the $\mathrm{m}-\mathrm{ZrO}_{2}$ fraction [45]. If this were the case, it would be hard to interpret the opposite trend that the strength of the identical but indented specimens increased with the fraction. This is because impressions by the indentation should behave as an additional defect besides the layer to aggravate the strength. Thus, an alternate rationale is required for the interpretation of the decrease in strength with the increase in the $\mathrm{t} \rightarrow \mathrm{m}$ phase transformation.

The possible involvement of the residual internal stress on the strength of the aged $\mathrm{t}$ $\mathrm{ZrO}_{2}$ was further examined using Vickers indentation in Figure 8. After conducting Vickers indentation on the surface aged at various temperatures, the strength increased with the aging temperatures for all the specimens indented at loads ranging from 9.8 to $490 \mathrm{~N}$. This result is analogues to the reports on the strengthening by LTD [22-24]. The increasing rate of strength with the aging temperature was highest at $98 \mathrm{~N}$ and reduced as the load increased. The strength of the specimens indented at $9.8 \mathrm{~N}$ was even higher than that of non-indented specimens at aging temperatures of $160-220^{\circ} \mathrm{C}$. The unexpected result was related to the residual stress around the indentation. The impression formed by the Vickers indent is generally described by a hemispherical compressively plasticized zone beneath the indent, surrounded by the elastic matrix. The elastic/plastic contact generates residual stresses around the indentation, which play a significant role in the fracture process of ceramics [46]. Particularly, the compressive residual stress originates from the constraint on the expanded indentation region from the unyielded material surrounding it [47]. Thus, the fracture toughness of indented brittle ceramics is given by the applied stress intensity factor and indentation residual stress intensity factor [48]. Herein, the influence of indentation on the strength of the aged 3Y-TZP is possibly related to the compressive residual stresses from both the indentation and the revelation of the compressive layer beneath the tensile surface.

The $\mathrm{t}-\mathrm{ZrO} \mathrm{O}_{2}$ and $\mathrm{m}-\mathrm{ZrO}_{2}$ grains on the surface of the aged specimens experience tensile and compressive stress, respectively $[15,16]$. The compressive residual stress can be manifested by the $\beta$ lattice constant in Figure 6, which is significantly smaller than $99.22^{\circ}$ of the constant of $\mathrm{m}-\mathrm{ZrO}_{2}$ compiled in the ICDD \# 00-037-1484. When an indenter is placed on 
the surface of the aged specimens, the residual compressive zone beneath the indenter and partially exposed compressive layer by the indentation contribute to retarded crack growth in the form of indentation residual stress intensity [48]. Furthermore, the $\mathrm{m}-\mathrm{ZrO}_{2}$ on the aged surface may transform back to $\mathrm{t}-\mathrm{ZrO}_{2}$ as the indentation expands and envelops the aged material in the highly compressive region beneath the indenter [47]. The decreased elastic modulus by LTD [49] may facilitate the envelopment because materials with low ratios of the modulus/strength easily accommodate the indentation volume into the plastically deformed zone beneath the indenter [50]. The freshly created compressive surface by indentation combined with the residual stress intensity factor may cause increased strength of the indented specimens in Figures 4 and 8 . The residual stress originates from hydrostatic compressive stress accompanying the $\mathrm{t} \rightarrow \mathrm{m}$ phase transformation in the plastic zone [51]. As the plastic zone size increases with the indent load, the residual tensile stress located on the edge of the impression, which is produced by mismatch tractions on the surrounding matrix by the plastically deformed zone [46], may play a role in the distraction of the compressive field. Consequently, the constructive influence of indentation on the strength of the aged specimens reduces at loads exceeding $196 \mathrm{~N}$ and nearly disappears at a load of $490 \mathrm{~N}$. Additionally, the complete disappearance at a load of $490 \mathrm{~N}$ may be associated with the decrease in residual stress due to lateral cracking [48].

The stress-induced martensitic $\mathrm{t} \rightarrow \mathrm{m}$ phase transformation is characterized by an athermal and diffusionless process; however, the kinetics of LTD involve isothermal and diffusion-controlled phase transformation [8]. When the initial $t \rightarrow m$ transformation occurred, the shape strain comprising shear and dilational strains exerts opposing stresses in the surrounding matrix to place a local internal stress that could cause further stressinduced $\mathrm{t} \rightarrow \mathrm{m}$ transformation leading to the autocatalytic transformation [40]. This can occur immediately at the moment of the crack propagation to contribute to the phase transformation toughening. In LTD, however, the opposing stresses are accumulated by the isothermal $t \rightarrow m$ transformation through the diffusion of oxygen vacancies and may be accommodated to trigger the $\mathrm{c} \rightarrow \mathrm{r}$ transformation. This is supported by the fact that the $\mathrm{c} \rightarrow \mathrm{r}$ transformation is a stress induced phase transformation [52] and the $\mathrm{c}-\mathrm{ZrO}_{2}$ content in 3Y-TZP decreases with prolonged aging time [20]. When the opposing stresses become large enough by aging at temperatures higher than $160{ }^{\circ} \mathrm{C}$, the remnant shear stresses expand abruptly the $\beta$ lattice constant in $\mathrm{m}-\mathrm{ZrO}_{2}$ from 99.03 to $99.11^{\circ}$ (Figure 6) to relieve the compressive stress in $\mathrm{m}-\mathrm{ZrO}_{2}$ resulting in additional tensile residual stress on the aged surface. The sudden increase in $\beta$ is likely related to the collapse of $t(101)$ peak and the preferred orientation of $\mathrm{m}(002)$ as observed in Figure 5. This is analogous to the autocatalytic effect in a diffusion-controlled manner. As LTD proceeds, thus, the fractions of $\mathrm{t}-\mathrm{ZrO}_{2}$ and $\mathrm{c}-\mathrm{ZrO}{ }_{2}$ decrease and those of $\mathrm{m}-\mathrm{ZrO}{ }_{2}$ and $\mathrm{r}-\mathrm{ZrO}{ }_{2}$ increase.

The $\mathrm{m}-\mathrm{ZrO} \mathrm{r}_{2}$ fraction on the surface aged at $160{ }^{\circ} \mathrm{C}$ was $52.2 \%$ in Figure 7 . The relaxation of the compressive stress is supported by the fact that the steady increase in the compressive stress in $\mathrm{m}-\mathrm{ZrO}_{2}$ with aging was halted but the tensile stress in $\mathrm{t}-\mathrm{ZrO}_{2}$ increased continuously when the $\mathrm{m}-\mathrm{ZrO}_{2}$ fraction was higher than approximately $50 \%$ [15]. In this case the aged specimens lose their strength with an increase in LTD and the strength becomes subject to the influence of the indentation as shown in Figures 7 and 8. Conversely, when the opposing stress is consumed only for the $c \rightarrow r$ transformation, the $\beta$ lattice parameter remains nearly constant at about $99.03^{\circ}$ and the aged strength increases with LTD possibly because the compressive stress in $\mathrm{m}-\mathrm{ZrO}_{2}$ overwhelms the tensile stress in the untransformed $\mathrm{t}-\mathrm{ZrO}_{2}$. This is the case where the indentation strength of specimens preaged at temperatures lower than $130^{\circ} \mathrm{C}$ increases slightly with LTD in Figures 7 and 8 . The transition of LTD dependence of the strength was observed from 3Y-TZP subjected to accelerated aging at $134^{\circ} \mathrm{C}$, where the transition occurred after $14.7 \mathrm{~h}$ of aging [53]. It should be noted that the $\mathrm{m}-\mathrm{ZrO}_{2}$ fraction that determines the dominancy of the residual stress state on the aged surface may not be fixed for 3Y-TZP but rather varies with the magnitude of the intrinsic or extrinsic residual stresses in specimens. 
As previously mentioned, the influence of LTD on the flexural strength of Y-TZP is controversial [22-30]. Based on observations of the indentation dependence of the strength of aged 3Y-TZP, controversies surrounding the effect of aging on the strength of 3Y-TZP might be rationalized by considering the residual stress state on the surface of the aged specimens. The argument of residual stress can facilitate to envision the mechanism for LTD in such that the oxygen vacancies in $\mathrm{t}-\mathrm{ZrO}_{2}$ under the residual tensile stress on the surface migrate into the bulk overcoming the activation barrier of $\sim 83 \mathrm{~kJ} / \mathrm{mol}$ along the residual stress gradient to relieve the internal stress in $\mathrm{t}-\mathrm{ZrO}_{2}$ lattice $[7,8,43]$. This study demonstrates that the stress state can be envisaged by the measurements of the indentation strength of 3Y-TZP after aging. The surface residual stresses can be encountered, not only by the $\mathrm{t} \rightarrow \mathrm{m}$ transformation, but during the preparation of strength specimens such as the severity of grinding for dimensioning sample size, heat treatment after machining, abnormal thermal expansion mismatch between 3Y-TZP specimens and a ceramic substrate where the specimens are placed during sintering, and thickness of the bending specimens. In clinical situations, the occlusal adjustment of the restoration may be a cause of surface residual stress, which may influence the longevity of the restorations.

\section{Conclusions}

Even LTD resistant 3Y-TZP containing $0.25 \% \mathrm{Al}_{2} \mathrm{O}_{3}$ underwent LTD in air, where no intentional water species were involved, once the internal residual stress is sufficiently large to induce $\mathrm{t} \rightarrow \mathrm{m}$ phase transformation. The transformation was accompanied by $\mathrm{c} \rightarrow \mathrm{r}$ transformation, which is responsible for the asymmetric broadening of the (101) peak of $\mathrm{t}-\mathrm{ZrO} \mathrm{r}_{2}$ lattice. The $\beta$ lattice constant of $\mathrm{m}-\mathrm{ZrO}_{2}$ lattice was highly contracted by LTD demonstrating compressive residual stress state in $\mathrm{m}-\mathrm{ZrO}_{2}$. The magnitude of $\beta$ depended on the build-up of opposing stress in the surrounding matrix imposed by the $t \rightarrow \mathrm{m}$ transformation. The influence of preaging temperature on the $\beta$ value and the indented strength of $3 \mathrm{Y}$-TZP suggested that as the $\mathrm{m}-\mathrm{ZrO}_{2}$ is under a heavy compressive stress at relatively early stage of LTD, the aged strength increases with LTD, and as the compressive stress is relaxed after an extensive LTD, the strength deteriorates with LTD. The transition occurred at the $\mathrm{m}-\mathrm{ZrO} 2$ fraction of $52 \%$ as determined by the Rietveld refinements.

Author Contributions: Conceptualization, D.-J.K.; methodology, K.-W.J., G.-U.Y. and D.-J.K.; validation, J.-S.H. and D.-J.K.; formal analysis, K.-W.J., G.-U.Y. and D.-J.K.; writing-original draft preparation, K.-W.J.; writing-review and editing, D.-J.K.; supervision, D.-J.K.; funding acquisition, J.-S.H. and D.-J.K. All authors have read and agreed to the published version of the manuscript.

Funding: This work was supported by the Korea Medical Device Development Fund grant funded by the Korea Government (the Ministry of Science and ICT, the Ministry of Trade, Industry and Energy, the Ministry of Health \& Welfare, the Ministry of Food and Drug Safety) (KMDF_PR_20200901_0105).

Institutional Review Board Statement: Not applicable.

Informed Consent Statement: Not applicable.

Data Availability Statement: The data presented in this study are available on request from the corresponding author.

Acknowledgments: The authors express their sincere gratitude to Daniel Lee for his support in the Rietveld refinements.

Conflicts of Interest: The authors declare no conflict of interest.

\section{References}

1. Stawarczyk, B.; Keul, C.; Eichberger, M.; Figge, D.; Edelhoff, D.; Lumkemann, N. Three generations of zirconia: From veneered to monolithic. Part I. Quintessence Int. 2017, 48, 369-380.

2. Ferrari, M.; Vichi, A.; Zarone, F. Zirconia abutments and restorations: From laboratory to clinical investigations. Dent. Mater. 2015, 31, e63-e76. [CrossRef] 
3. Sailer, I.; Makarov, N.A.; Thoma, D.S.; Zwahlen, M.; Pjetursson, B.E. All-ceramic or metal-ceramic tooth-supported fixed dental prostheses (FDPs)? A systematic review of the survival and complication rates. Part I: Single crowns (SCs). Dent. Mater. 2015, 31, 603-623. [CrossRef]

4. Stawarczyk, B.; Keul, C.; Eichberger, M.; Figge, D.; Edelhoff, D.; Lumkemann, N. Three generations of zirconia: From veneered to monolithic. Part II. Quintessence Int. 2017, 48, 441-450. [PubMed]

5. Kocjana, A.; Cotič, J.; Kosmač, T.; Jevnikar, P. In Vivo aging of zirconia dental ceramics- Part I: Biomedical grade 3Y-TZP. Dent. Mater. 2021, 37, 443-453. [CrossRef]

6. Miragaya, L.M.; Guimarães, R.B.; Souza, R.O.A.E.; Santos Botelho, G.D.; Antunes Guimarães, J.G.; da Silva, E.M. Effect of intra-oral aging on $\mathrm{t} \rightarrow \mathrm{m}$ phase transformation, microstructure, and mechanical properties of Y-TZP dental ceramics. J. Mech. Behav. Biomed. Mater. 2017, 72, 14-21. [CrossRef]

7. Kim, D.-J.; Jung, H.-J.; Cho, D.-H. Phase transformations of $\mathrm{Y}_{2} \mathrm{O}_{3}$ and $\mathrm{Nb}_{2} \mathrm{O}_{5}$ doped tetragonal zirconia during low temperature aging in air. Solid State Ion. 1995, 80, 67-73. [CrossRef]

8. Kim, D.-J.; Jung, H.-J.; Jang, J.-W.; Lee, H.-L. Fracture toughness, ionic conductivity, and low temperature phase stability of tetragonal zirconia co-doped with $\mathrm{Y}_{2} \mathrm{O}_{3}$ and $\mathrm{Nb}_{2} \mathrm{O}_{5}$. J. Am. Ceram. Soc. 1998, 81, 2309-2314. [CrossRef]

9. Capel, F.; Moure, C.; Durán, P.; González-Elipe, A.R.; Caballero, A. Titanium local environment and electrical conductivity of $\mathrm{TiO}_{2}$-doped stabilized tetragonal zirconia. J. Mater. Sci. 2000, 35, 345-352. [CrossRef]

10. Eichler, A. Tetragonal Y-doped zirconia: Structure and ion conductivity. Phys. Rev. B 2001, 64, 174103. [CrossRef]

11. Badwal, S.P.S.; Nardella, N. Formation of Monoclinic Zirconia at the Anodic Face of Tetragonal Zirconia Polycrystalline Solid Electrolytes. Appl. Phys. Sol. Surf. 1989, 49, 13-24. [CrossRef]

12. Chevalier, J.; Gremillard, L.; Virkar, A.V.; Clarke, D.R. The tetragonal-monoclinic transformation in zirconia: Lessons learned and future trends. J. Am. Ceram. Soc. 2009, 92, 1901-1920. [CrossRef]

13. Chevalier, J.; Cales, B.; Drouin, J.M. Low temperature aging of Y-TZP ceramics. J. Am. Ceram. Soc. 1999, 82, 2150-2154. [CrossRef]

14. Chevalier, J.; Gremillard, L.; Deville, S. Low-temperature degradation of zirconia and implications for biomedical implants. Annu. Rev. Mater. Res. 2007, 37, 1-32. [CrossRef]

15. Arita, M.; Takahashi, Y.; Pezzotti, G.; Shishido, T.; Masaoka, T.; Sano, K.; Yamamoto, K. Environmental stability and residual stresses in zirconia femoral head for total hip arthroplasty: In vitro aging versus retrieval studies. Biomed. Res. Int. 2015, 2015, 638502. [CrossRef] [PubMed]

16. Lughi, V.; Sergo, V. Low temperature degradation-aging-of zirconia: A critical review of the relevant aspects in dentistry. Dent. Mater. 2010, 26, 807-820. [CrossRef] [PubMed]

17. Garvie, R.C.; Nicholson, P.S. Phase analysis in zirconia systems. J. Am. Ceram. Soc. 1972, 55, 303-305. [CrossRef]

18. Toraya, H.; Yoshimura, M.; Somiya, S. Calibration curve for quantitative analysis of the monoclinic-tetragonal $\mathrm{ZrO}_{2}$ systems by X-ray diffraction. J. Am. Ceram. Soc. 1984, 67, C119-C121.

19. Schmid, H.K. Quantitative analysis of polymorphic mixes of zirconia by X-ray diffraction. J. Am. Ceram. Soc. 1987, 70, 367-376. [CrossRef]

20. Kosmač, T.; Kocjan, A. Ageing of dental zirconia ceramics. J. Eur. Ceram. Soc. 2012, 32, 2613-2622. [CrossRef]

21. Arata, A.; Campos, T.M.; Machado, J.P.; Lazar, D.R.; Ussui, V.; Lima, N.B.; Tango, R.N. Quantitative phase analysis from X-ray diffraction in Y-TZP dental ceramics: A critical evaluation. J. Dent. 2014, 42, 1487-1494. [CrossRef]

22. Pereira, G.K.R.; Muller, C.; Wandscher, V.F.; Rippe, M.P.; Kleverlaan, C.J.; Valandro, L.F. Comparison of different low-temperature aging protocols: Its effects on the mechanical behavior of Y-TZP ceramics. J. Mech. Behav. Biomed. Mater. 2016, 60, 324-330. [CrossRef] [PubMed]

23. Guilardi, L.F.; Pereira, G.K.R.; Gundel, A.; Rippe, M.P.; Valandro, L.F. Surface micro-morphology, phase transformation, and mechanical reliability of ground and aged monolithic zirconia ceramic. J. Mech. Behav. Biomed. Mater. 2017, 65, 849-856. [CrossRef] [PubMed]

24. Mota, Y.A.; Cotes, C.; Carvalho, R.F.; Machado, J.P.B.; Leite, F.P.P.; Souza, R.O.A.; Özcan, M. Monoclinic phase transformation and mechanical durability of zirconia ceramic after fatigue and autoclave aging. J. Biomed. Mater. Res. B. Appl. Biomater. 2017, 105, 1972-1977. [CrossRef] [PubMed]

25. Ban, S.; Sato, H.; Suehiro, Y.; Nakanishi, H.; Nawa, M. Biaxial flexure strength and low temperature degradation of $\mathrm{Ce}-\mathrm{TZP} / \mathrm{Al}_{2} \mathrm{O}_{3}$ nanocomposite and Y-TZP as dental restoratives. J. Biomed. Mater. Res. B. Appl. Biomater. 2008, 87, 492-498. [CrossRef]

26. Flinn, B.D.; Raigrodski, A.J.; Singh, A.; Mancl, L.A. Effect of hydrothermal degradation on three types of zirconias for dental application. J. Prosthet. Dent. 2014, 112, 1377-1384. [CrossRef]

27. Kim, H.T.; Han, J.S.; Yang, J.H.; Lee, J.B.; Kim, S.H. The effect of low temperature aging on the mechanical property \& phase stability of Y-TZP ceramics. J. Adv. Prosthodont. 2009, 1, 113-117.

28. De Souza, G.M.; Zykus, A.; Ghahnavyeh, R.R.; Lawrence, S.K.; Bahr, D.F. Effect of accelerated aging on dental zirconia-based materials. J. Mech. Behav. Biomed. Mater. 2017, 65, 256-263. [CrossRef]

29. Muñoz, E.M.; Longhini, D.; Antonio, S.G.; Adabo, G.L. The effects of mechanical and hydrothermal aging on microstructure and biaxial flexural strength of an anterior and a posterior monolithic zirconia. J. Dent. 2017, 63, 94-102. [CrossRef]

30. Kelch, M.; Schulz, J.; Edelhoff, D.; Sener, B.; Stawarczyk, B. Impact of different pretreatments and aging procedures on the flexural strength and phase structure of zirconia ceramics. Dent. Mater. 2019, 35, 1439-1449. [CrossRef] 
31. Kelly, J.R.; Giordano, R.; Pober, R.; Cima, M.J. Fracture surface analysis of dental ceramics: Clinically failed restorations. Int. J. Prosthodont. 1990, 3, 430-440.

32. Koenig, V.; Vanheusden, A.J.; Le Goff, S.O.; Mainjot, A.K. Clinical risk factors related to failures with zirconia-based restorations: An up to 9-year retrospective study. J. Dent. 2013, 41, 1164-1174. [CrossRef] [PubMed]

33. Coldea, A.; Swain, M.V.; Thiel, N. In-Vitro strength degradation of dental ceramics and novel PICN material by sharp indentation. J. Mech. Behav. Biomed. Mater. 2013, 26, 34-42. [CrossRef] [PubMed]

34. Zhang, Y.; Lee, J.J.; Srikanth, R.; Lawn, B.R. Edge chipping and flexural resistance of monolithic ceramics. Dent. Mater. 2013, 29, 1201-1208. [CrossRef] [PubMed]

35. Sulaiman, T.A.; Abdulmajeed, A.A.; Delgado, A.; Donovan, T.E. Fracture rate of 188695 lithium disilicate and zirconia ceramic restorations after up to 7.5 years of clinical service: A dental laboratory survey. J. Prosthet. Dent. 2020, 123, 807-810. [CrossRef] [PubMed]

36. International Organization for Standardization. ISO 18754:2013. Fine Ceramics (Advanced Ceramics, Advanced Technical Ceramics)Determination of Density and Apparent Porosity; ISO: Geneva, Switzerland, 2013.

37. International Organization for Standardization. ISO 6872:2015. Dentistry - Ceramic Materials; ISO: Geneva, Switzerland, 2015.

38. Matsui, K.; Nakamura, K.; Kumamoto, A.; Yoshida, H.; Ikuhara, Y. Low-temperature degradation in yttria-stabilized tetragonal zirconia polycrystal doped with small amounts of alumina: Effect of grain-boundary energy. J. Eur. Ceram. Soc. 2016, 36, 155-162. [CrossRef]

39. Becher, P.F.; Swain, M.V. Grain-size-dependent transformation behavior in polycrystalline tetragonal zirconia. J. Am. Ceram. Soc. 1992, 75, 493-502. [CrossRef]

40. Kelly, P.M.; Rose, L.R.F. The martensitic transformation in ceramics-its role in transformation toughening. Prog. Mater. Sci. 2002, 47, 463-557. [CrossRef]

41. Schubert, H. Anisotropic thermal expansion coefficients of $\mathrm{Y}_{2} \mathrm{O}_{3}$-stabilized tetragonal zirconia. J. Am. Ceram. Soc. 1986, 69, 270-271. [CrossRef]

42. Kim, D.-J.; Becher, P.F.; Hubbard, C.R. Effect of $\mathrm{Nb}_{2} \mathrm{O}_{5}$ alloying on thermal expansion anisotropy of $2 \mathrm{~mol}_{\%} \mathrm{Y}_{2} \mathrm{O}_{3}$-stabilized tetragonal $\mathrm{ZrO}_{2}$. J. Am. Ceram. Soc. 1993, 76, 2904-2908. [CrossRef]

43. Kim, D.-J. Influence of aging environment on low temperature degradation of tetragonal zirconia alloys. J. Eur. Ceram. Soc. 1997, 17, 897-903. [CrossRef]

44. Kim, D.-J. Effect of $\mathrm{Ta}_{2} \mathrm{O}_{5}, \mathrm{Nb}_{2} \mathrm{O}_{5}$ and $\mathrm{HfO}_{2}$ alloying on transformability of $\mathrm{Y}_{2} \mathrm{O}_{3}$-stabilized tetragonal $\mathrm{ZrO}_{2}$. J. Am. Ceram. Soc. 1990, 73, 115-120. [CrossRef]

45. Kohorst, P.; Borchers, L.; Strempel, J.; Stiesch, M.; Hassel, T.; Bach, F.W.; Hübsch, C. Low-temperature degradation of different zirconia ceramics for dental applications. Acta Biomater. 2012, 8, 1213-1220. [CrossRef] [PubMed]

46. Lawn, B.R.; Evans, A.G.; Marshall, D.B. Elastic/plastic indentation damage in ceramics: The median/radial crack system. J. Am. Ceram. Soc. 1980, 63, 574-581. [CrossRef]

47. Huang, S.; Binner, J.G.P.; Vaidhyanathan, B.; Todd, R.I. Quantitative analysis of the residual stress and dislocation density distributions around indentations in alumina and zirconia toughened alumina (ZTA) ceramics. J. Eur. Ceram. Soc. 2014, 34, 753-763. [CrossRef]

48. Pajares, A.; Guiberteau, F.; Steinbrech, R.W.; Dominguez-Rodriguez, A. Residual stresses around Vickers indents. Acta. Metall. Mater. 1995, 43, 3649-3659. [CrossRef]

49. Vatali, A.; Kontonasaki, E.; Kavouras, P.; Kantiranis, N.; Papadopoulou, L.; Paraskevopoulos, K.K.; Koidis, P. Effect of heat treatment and in vitro aging on the microstructure and mechanical properties of cold isostatic-pressed zirconia ceramics for dental restorations. Dent. Mater. 2014, 30, e272-e282. [CrossRef]

50. Munoz-Tabares, J.; Jiménez-Piqué, E.; Reyes-Gasga, J.; Anglada, M. Microstructural changes in 3Y-TZP induced by scratching and indentation. J. Eur. Ceram. Soc. 2012, 32, 3919-3927. [CrossRef]

51. Liang, K.; Gu, K. Transformation driving force for indentation cracking in zirconia ceramics. J. Am. Ceram. Soc. 1993, 76, 3144-3146. [CrossRef]

52. Hasegawa, H.; Hioki, T.; Kamigaito, O. Cubic-to-rhombohedral phase transformation in zirconia by ion implantation. J. Mater. Sci. Lett. 1985, 4, 1092-1094. [CrossRef]

53. Cotič, J.; Jevnikar, P.; Kocjan, A. Ageing kinetics and strength of airborne-particle abraded 3Y-TZP ceramics. Dent. Mater. 2017, 33, 847-856. [CrossRef] [PubMed] 